\title{
CAPABILITIES OF LASER RADIATION FOR IMPROVEMENT OF ELECTRODE WIRE QUALITY
}

\author{
S.B. SHEVCHENKO ${ }^{1}$, I.V. KRIVTSUN ${ }^{1}$, L.F. GOLOVKO ${ }^{1}$, A.N. LUTAJ ${ }^{1}$ and V.P. SLOBODYANYUK ${ }^{2}$ \\ ${ }^{1}$ NTUU «Kiev Polytechnic Institute» \\ 37 Pobeda Ave., 03056, Kiev, Ukraine. E-mail: leongolovko@gmail.com \\ ${ }^{2} \ll$ PlasmaTec» Company \\ 13/300 Khmelnitskoe Shosse, 20136, Vinnitsa, Ukraine
}

\begin{abstract}
Analysis of the processes of manufacturing wire electrodes for semi-automatic welding was performed, structure, quantitative chemical and phase composition of the wire surface layer before and after copper coating deposition were studied, and geometrical dimensions, location depth and relative quantity of nonmetallic inclusions in the coating were determined. Possibilities of removal of such nonmetallic inclusions by laser radiation with $10.6 \mu \mathrm{m}$ wave length were studied at different treatment parameters. Technology of laser cleaning of welding wire surface was proposed, which is performed before copper coating deposition. An experimental laser process complex was developed to verify development results under conditions close to those in production. 10 Ref., 15 Figures.
\end{abstract}

Keywords: welding wire, nonmetallic inclusions, oxides, laser radiation, absorptance, temperature, simulation, heating, evaporation, residual stresses

Semi-automatic wire electrode welding is widely applied in various industries. Steel wire of $0.8-$ $1.6 \mathrm{~mm}$ diameter with electroplated copper coating is the most often used as welding electrode in this case. The welding process and its quality greatly depend on uniformity of chemical composition of surface layer of the steel wire proper and the resulting quality of the copper coating.

In this connection, the steel wire surface is cleaned by various methods before the copper coating deposition: cleaning from rust and lubrication by metal brushes simultaneously with row winding [1], mechanical cleaning by drawing it through a strand of one or several turns of welding wire proper (loop in the form of figure-ofweight) [2]. The most acceptable is the process of cleaning by repeated drawing through dies, but it significantly increases the wire manufacturing cost - by more than 2 times [1,3]. Moreover, mechanical cleaning leads to instantaneous corrosion of the cleaned surface, higher wear of the guides and tip of the welding machine.

Chemical cleaning also causes corrosion of both the wire proper, and equipment parts contacting it. Used for these purpose is the method of electrolyte-discharge cleaning, which includes cathode processing of welding wire in electrolyte - water solution of sodium chloride or carbonate [4].

During welding wire drawing, dry lubricant based on fatty acid salts is used. Presence of remains of process lubricant on the wire violates the electric contact, leading to arc interruption and welding quality deterioration.

Ultrasound application for welding wire cleaning from remains of process lubrication is known [5]. At wire passing through ultrasonic cleaning bath, the remains of process lubrication and contamination are softened, and washed off by the cleaning solution. At selection of the cleaning solution it should be taken into account that the cleaning media should have high chemical activity, and should effectively loosen, break up or dissolve the remaining contamination. Moreover, ultrasonic cleaning at treatment in liquid media gives rise to cavitation phenomenon, namely collapse of gas bubbles, forming at fluid compression and expansion. Cavitation is accompanied by generation of high dynamic hydrostatic pressures, which tear off the contamination particles sticking to the metal surface. The degree of ultrasonic cleaning of welding wire from remains of process lubrication is influenced by cleaner type, its concentration and temperature and drawing speed. Drawing speed has an important influence directly on the quality of ultrasonic cleaning. At application of one and the same cleaner and the same concentrations and temperatures of working solution, the results of wire cleaning will be different at different speeds - remaining amount of process lubrication will, nonetheless, be the smaller, the lower the wire drawing speed (we are talking about drawing speeds of $2-3 \mathrm{~m} / \mathrm{s}$ ). 
Application of cleaned wire in modern welding equipment allows avoiding violation of electric contact during welding, and, therefore, arc interruption, improving its stability, and reducing the influence of other factors impairing the weld quality.

The above data are indicative of the fact that a whole number of different cleaning methods has been developed so far for welding wire cleaning from various contamination, allowing an only partial reduction of electrode material spattering in welding, but not solving the whole problem.

The problem of improvement of welding wire quality can be solved in several ways: improvement of high-quality copper coating deposition technology, significant reduction of wire surface roughness through application of various kinds of polishing operations, and development of new methods of high-efficient protective coating deposition.

Expensive copper-coated welding wire is mostly used now. The main purpose of the copper coating consists in ensuring good electric contact at supplying welding current to the wire. In terms of ecology, however, application of copper coating on welding wire leads to hazardous contamination of production facilities and environment. Moreover, weld quality is impaired at coppercoated wire application.

As an alternative to copper coating, the leading world manufacturers have mastered production of wire with ground and polished surface. Its cost is $5-8 \%$ higher than that of copper-coated wire. The disadvantage of polished wire is its intensive corrosion in humid air atmosphere.

Plasma-arc and spark methods of surface treatment have been developed. Plasma-arc method allows performing non-polluting, high-quality and comparatively inexpensive cleaning and degassing of welding wire. Its thermovacuum treatment is performed at the same time that even further improves welding quality. The cost of plasma-arc cleaning of welding wire is essentially lower than that of acid or arc cleaning.

Spark method of metal surface cleaning seems promising. This method also is non-polluting and cost-effective.

Analysis of various methods and devices for cleaning the welding wire surface before copper coating deposition, given in [6], showed certain prospects for application of laser treatment of the surface for these purposes that is exactly the objective of this study.

Welding wire, produced by cold drawing of hot-rolled billet from Sv-08G2S steel has become the most widely applied in gas-shielded mechanized welding [7]. The final operation of welding wire manufacturing (before its winding onto cassettes) is deposition of copper coating of thickness $h=0.15-0.60 \mu \mathrm{m}$. The lower thickness limit is determined by formation of a discontinuous (islet) layer, and the upper one - by impact toughness lowering and initiation of solidification cracks at exceeding the limit concentration of copper in welds.

The purpose of copper coating is to protect the welding wire from corrosion in shielding gas atmosphere, lowering the contact resistance of «electrode wire-current-conducing tip» pair, improving the conditions of initial arc excitation and reducing the wear of working channel of copper current-carrying tip.

The abovementioned functional characteristics of copper coating are determined by the degree of layer uniformity and its adhesion. The latter is particularly important at application of various feeding mechanisms in welding, the operation of which largely depends on copper coating adhesion, which, in its turn, determines the arcing stability [8].

PWI studied the copper coating on welding wire, produced by the method of electrolytic deposition in copper sulphate solution [8]. It is found that immediately after deposition the copper layer had considerable concentration of pores and microcracks. Coating deformation in the die with application of lubricant, which was supposed to cover the defects, did not improve the layer quality.

In this connection, at the first stage of this work it is necessary to perform detailed analysis of copper coating defects, reveal the causes for and mechanisms of their formation and develop on this base a highly effective method and equipment for an essential improvement of welding wire quality.

Materials and experimental procedure. Three object types were studied: $1 \mathrm{~mm}$ copper-coated wire after drawing in the last die; 1 and $3 \mathrm{~mm}$ uncoated wire directly after drawing; and $1 \mathrm{~mm}$ wire after polishing.

Investigations were performed in MIM-8 metallographic microscope with application of WEB-camera with 3 Mpix resolution. To detect nonmetallic inclusions, polarized light was used in addition to white light. It is known that in the above-mentioned light nonmetallic inclusions can be seen on micrographs as light regions against a dark background. Two types of surfaces were analyzed - microsection surfaces and wire surfaces without any preparation. Microsections were prepared in the plane, normal to the wire axis, and in the planes forming approximately 


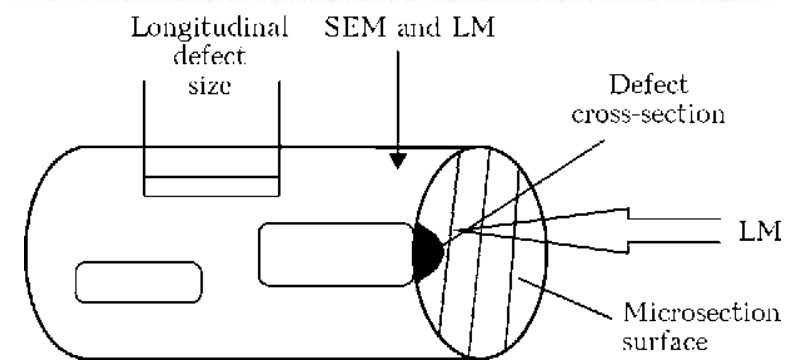

Figure 1. Schematic of object filming

$30^{\circ}$ angle (angle lap) with the axis. $4 \% \mathrm{HNO}_{3}$ solution in alcohol was used as etchant.

Cylindrical surfaces were studied in scanning electron microscope (SEM) in reflected and secondary electrons. In some points (electron probe diameter of approximately $50 \mathrm{~nm}$ ) X-ray spectral probe microanalysis (RSPMA) was used to perform complete chemical analysis. Micrographs were analyzed by the procedure described in [9].

Figure 1 shows the schematic of taking micrographs at examination by light microscopy (LM) and SEM methods.

Investigation results and their discussion. Figure 2 gives micrographs of copper coating surface, taken by LM method. The coating is nonuniform - regions, not having the colour characteristic for copper, are observed.

The low depth of resolution of light microscope does not allow a more detailed description of the observed layer defects. Electron micrographs of different coating regions (Figure 3 ) show a large quantity of surface defects of an elongated shape with the long axis coinciding with the direction of

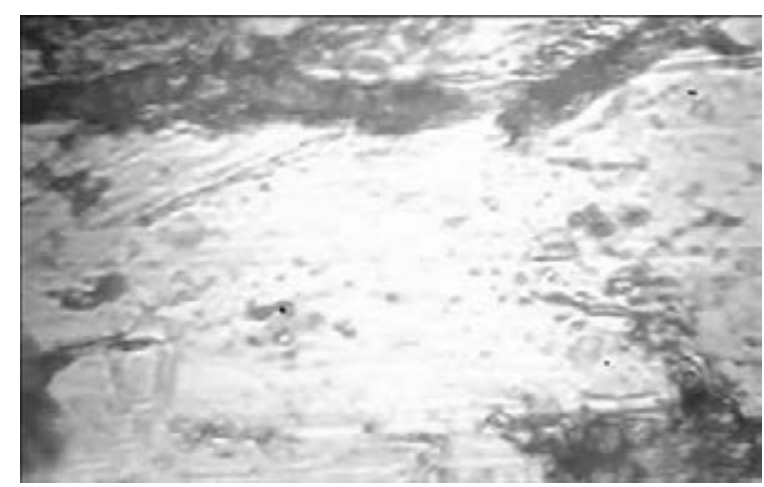

Figure 2. Micrograph $(\times 2000)$ of copper coating surface (LM)

wire drawing through the die. An essential difference in the contrast of micrographs taken in the secondary (Figure 3, $a, c$ ) and reflected electrons (Figure $3, b, d$ ) is attributable to the following features of the above procedures. At filming in reflected electrons a method of electron recording, minimizing the contrast topographic component, was realized. Thus, the composition (phase) contrast prevails in the above micrographs: micrograph brightest regions correspond to sample regions enriched in heavier elements (with greater atomic mass).

Therefore, the extensive light regions in $\mathrm{Fi}^{-}$ gure $3, b, d$ are the copper zones or steel surface. It is impossible to determine which regions correspond to copper or to iron, based on just the difference in contrast, because of the closeness of atomic masses of the above elements. Spots and grey film on the micrographs in Figure 3, $a$, $b$ are the remains of process lubricant used in
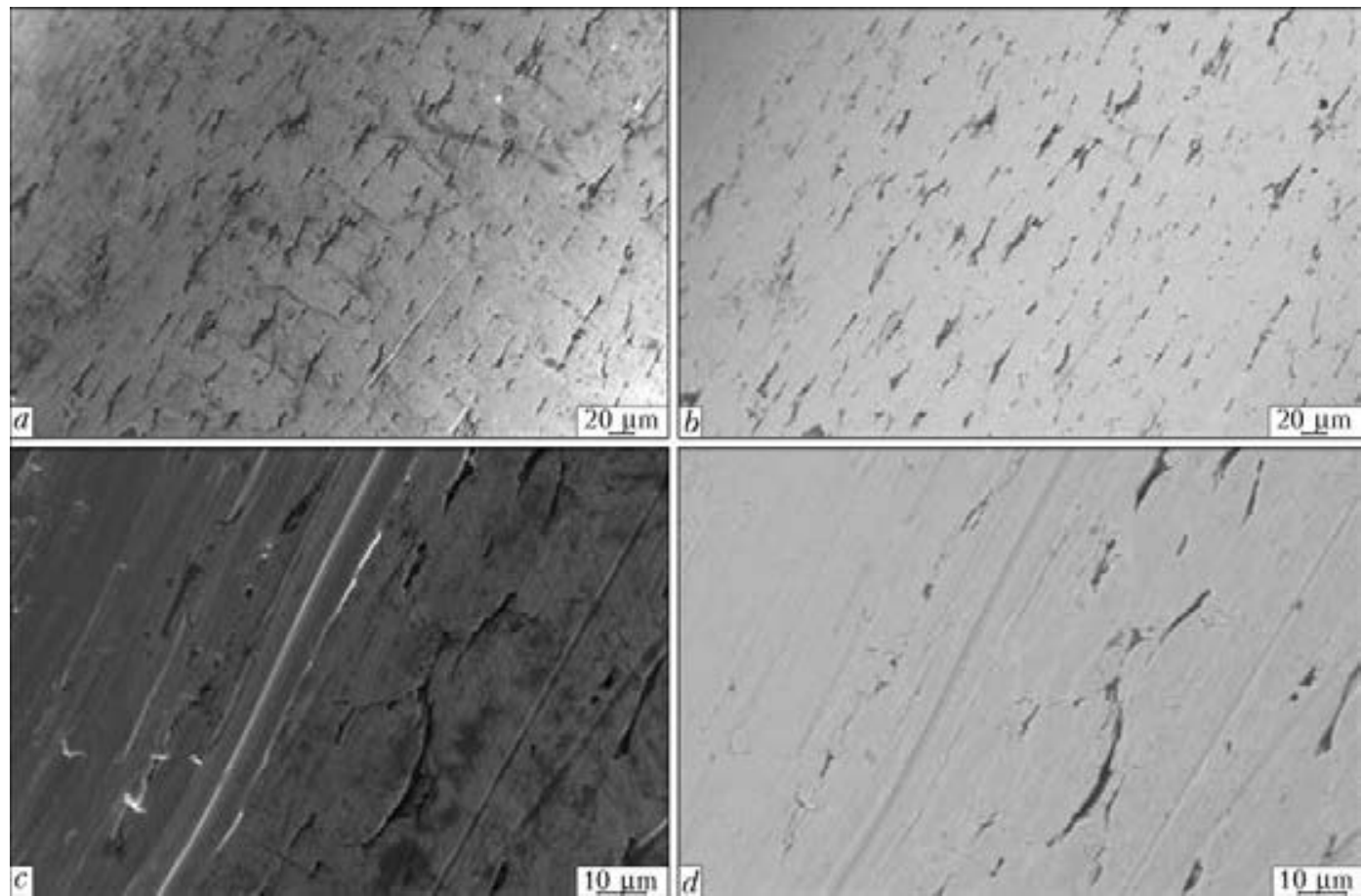

Figure 3. Electron micrographs of different sections of the copper coating: $a, c-$ in secondary; $b, d-$ in reflected electrons $(a, b-\times 500 ; c, d-\times 2000)$ 


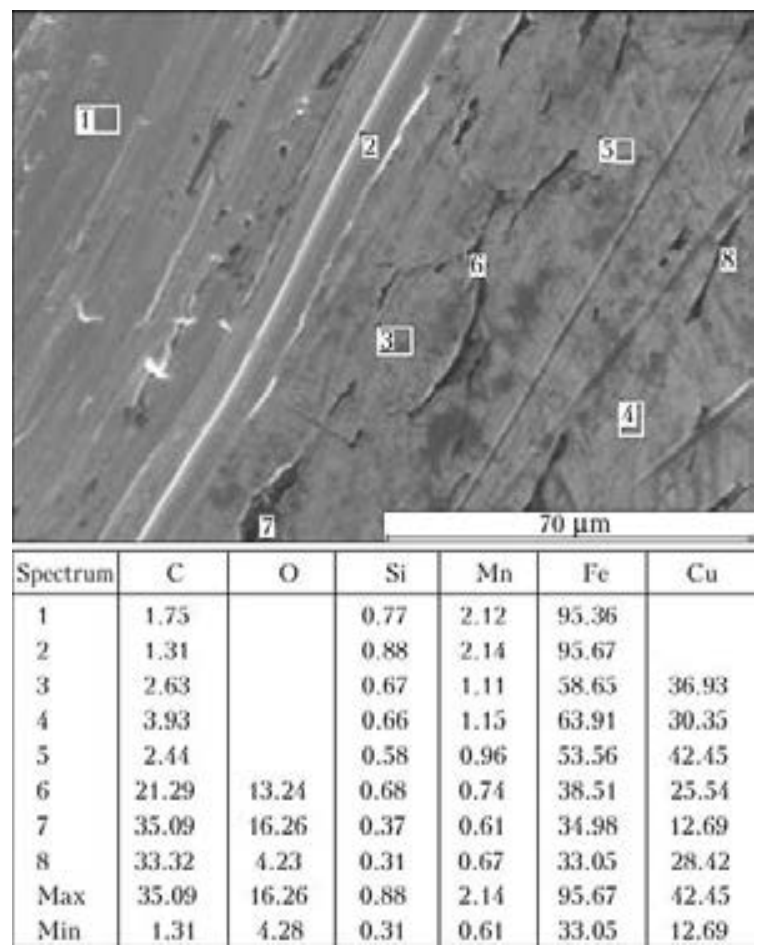

Figure 4. Results of X-ray spectral microprobe analysis of the composition of sections marked in the micrograph

drawing. RSPMA results of the composition of various regions of the sample (Figure 4) allow stating that a large part of volume defects are iron oxides, coated by a thin copper layer. $\mathrm{Fi}^{-}$ gure 5 gives a more visual representation of RSPMA results, from which it follows that the sample surface consists of two zones: region without coating traces taking $38 \%$ of the entire surface area, and coating region with coarse inclusions of iron oxides. Coating absence over a substantial surface area, in our opinion, is related to poor quality of wire surface treatment before coating deposition (incomplete removal of the lubricant, insufficient degreasing, etc.).

Weak adhesion of the coating in such regions leads to its removal (stripping off) during passage through the dies.

Let us analyze the possible causes for and mechanisms of iron oxide appearance in the wire surface layer. The first is that a hot-rolled billet has scale on its surface, which is pressed into the steel during drawing.

Phase composition of scale on rod wire from Sv-08G2S steel and methods to remove it were studied in [10]. It is shown that the oxide is removed completely, if mechanical removal of scale is performed at the temperature of wustite ( $\mathrm{FeO}$ ) existence, i.e. at $~ 950{ }^{\circ} \mathrm{C}$. This is exactly the technology of scale removal that was realized in the objects of this study. Considering the high drawing speed $(\sim 12 \mathrm{~m} / \mathrm{s})$, it can be assumed that the forces of friction in the point of billet contact with the tool result in heating up to high temperatures, that leads to wire surface oxidation.

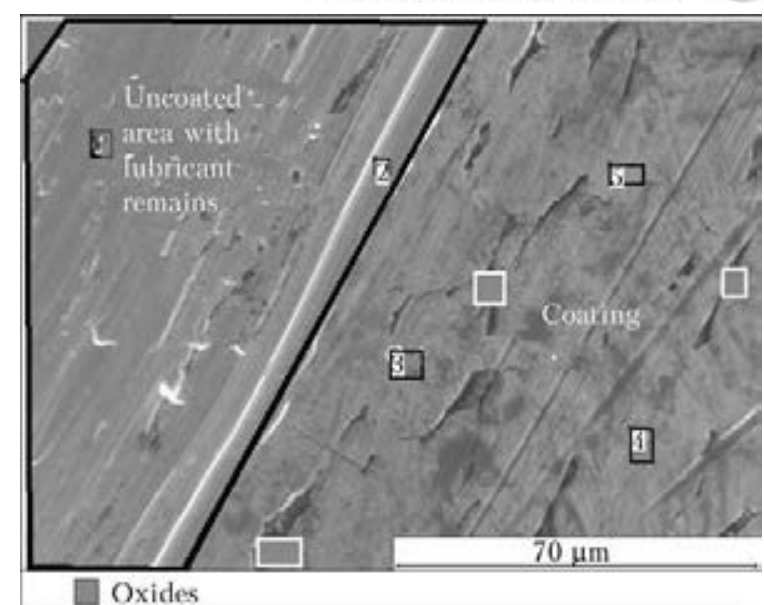

Figure 5. Electron micrograph of copper coating

Metallographic examination of transverse microsections confirmed that defects have considerable dimensions. Data in Figure 6 give an idea of defect depth and width.

It is clear that oxides of such dimensions could not have formed by the above mechanism. As shown by metallographic analysis of transverse microsections of $3 \mathrm{~mm}$ wire (Figure 7 ), oxides of the above dimensions are present in the steel inner volumes. Therefore, the initial billet contains iron oxides, located at different distance from the surface.

At passing through each die, oxides located near the billet surface become exposed ( $F i-$ gure 8), thus increasing their surface concentration. The suggested defect formation mechanism is confirmed by absence of plastic deformation traces, characteristic for steel drawing, on defect surface. Therefore, the die was in direct contact with the oxide.

Let us note in conclusion that polishing of final diameter wire, while essentially reducing the surface roughness (Figure 9), did not in any way
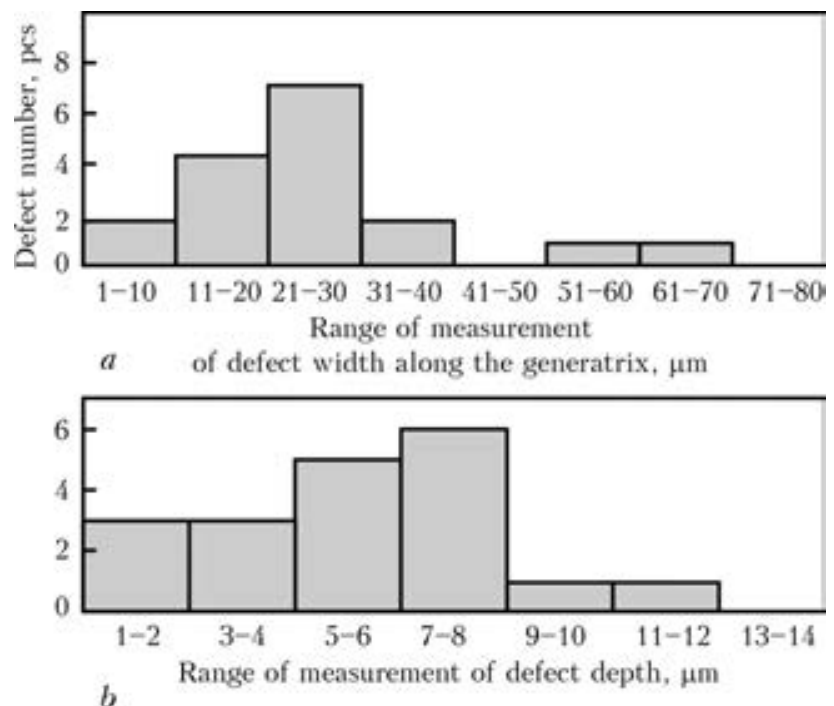

Figure 6. Histogram of linear defect dimensions: $a$ - width; $b$ - depth of surface defects 


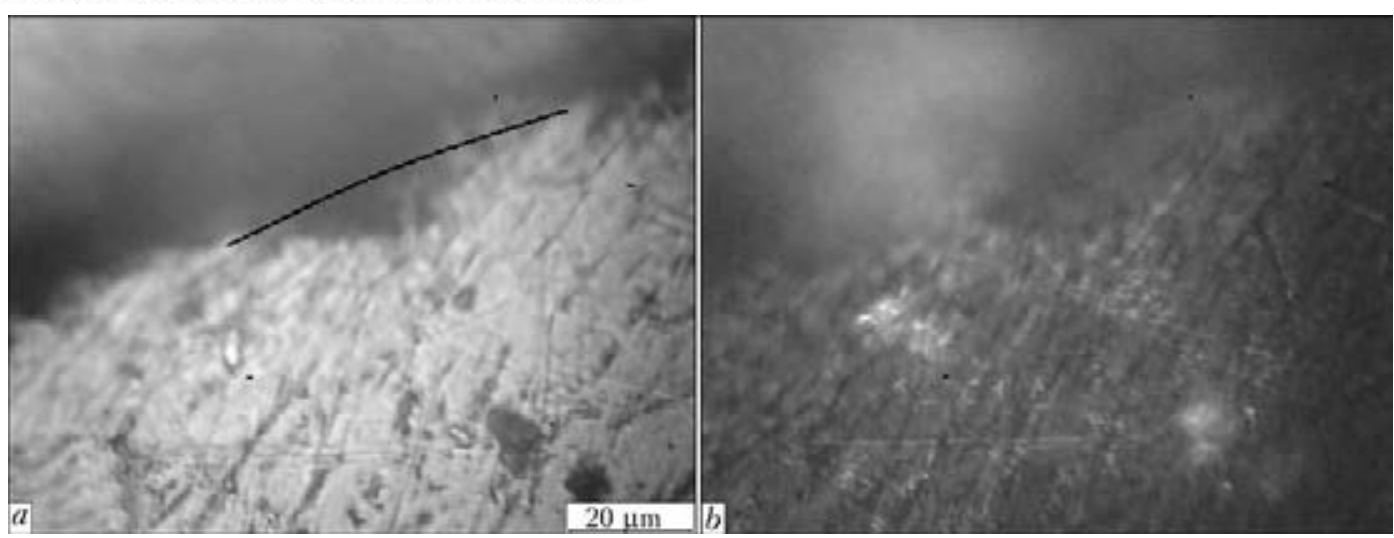

Figure 7. Micrographs of end surface of $3 \mathrm{~mm}$ wire in white $(a)$ and polarized $(b)$ light

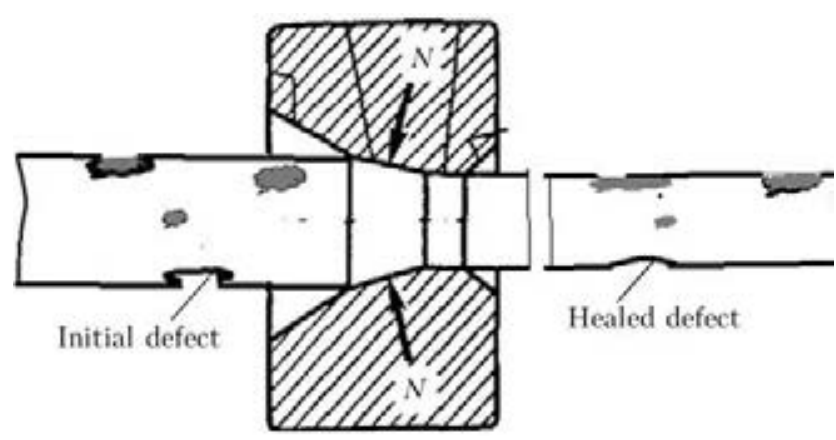

Figure 8. Schematic of defect formation on wire surface at drawing

affect the surface oxide concentration (Figure 10).

Analysis of the results of performed research showed that the copper coating, galvanically deposited on the steel welding wire Sv-08G2S, has a considerable number of defects, which are exactly the cause for metal spattering in welding.
Coating defects are due to two main causes insufficiently well treated surface of the wire before coating deposition, and large quantity of nonmetallic inclusions in its surface layer, their concentration changing in a broad range (from 20 up to $40 \%$ ). Oxide location depth is not more than 20-30 $\mu \mathrm{m}$.

High concentration of iron oxides on the surface of final diameter wire is accounted for by their successive exposure at passing through the dies. Wire polishing does not affect the surface iron oxide concentration.

Development of experimental equipment for laser treatment of welding wire. Experimental investigations related to welding wire treatment by laser radiation, were performed to assess the possibility of removing from its surface layer the nonmetallic inclusions present in it after the last drawing stage.

It is known that infrared radiation with $10.6 \mu \mathrm{m}$ wave length is poorly absorbed by metals
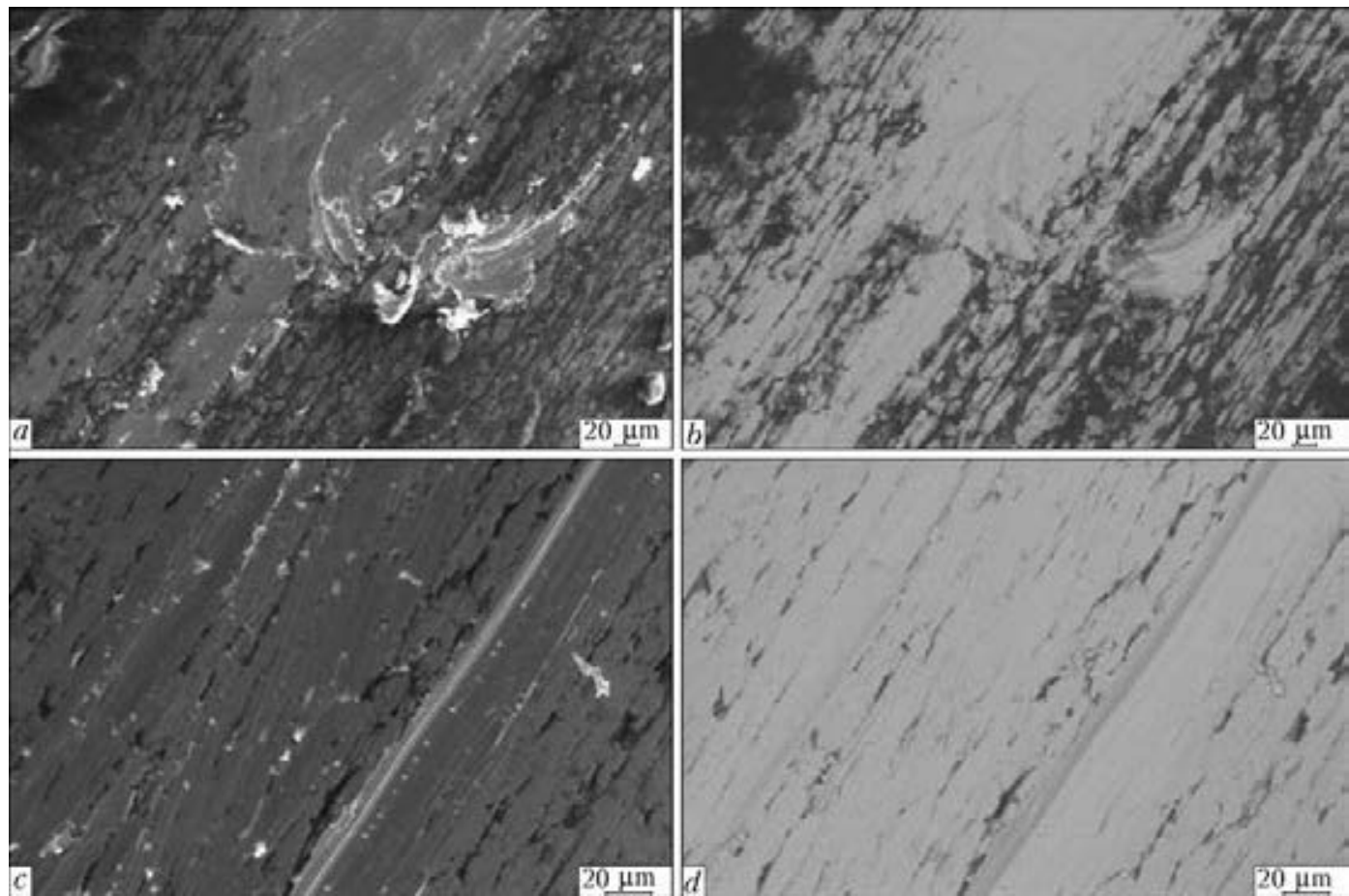

Figure 9. Electron micrographs of $1 \mathrm{~mm}$ wire surface after leaving the die $(a, b)$ and after subsequent polishing $(c, d)$ 
and readily absorbed by dielectrics (oxides). Therefore, for selective removal of oxide inclusions, the welding wire surface was treated by continuous radiation of $\mathrm{CO}_{2}$-laser system «Kometa-2» of $1200 \mathrm{~W}$ output power (Figure 11, $a$ ). Laser radiation with multimode distribution of intensity $\mathrm{TEM}_{20}$ was focused on the moving wire surface by a plane-spherical lens from $\mathrm{KCl}$ with $300 \mathrm{~mm}$ focal distance. Here, the diameter of the laser beam in the treatment plane was equal to $1 \mathrm{~mm}$. Shielding gas (argon) was fed into the zone of laser beam impact. A special device was developed for welding wire orientation and displacement relative to the laser beam, the schematic of which is given in Figure 11, $b$. The device consists of a metal case on four supports 1 , on which electric motor with reduction gear and receiving cassette 2 and mechanism for fixation of the cassette with wire displacement speed sensor 3 are mounted. Wire 4 is forcedly reeled off initial cassette 7 at preset speed, is directed by guide rollers and is fed into the inductor, where its heating up to tempering temperature is performed in inert gas atmosphere to relieve residual stresses. In the next stage, at wire passing through the next two roller pairs 5 , which orient it relative to the axis of the focused laser beam 6 , its irradiation is performed. As a result of selective absorption, oxide inclusions are removed from the wire surface through evaporation. To perform this operation, a system of laser radiation focusing based on torroidal mirror, should be built into the wire drawing machine.

Experimental studies were conducted in a somewhat simplified test facility, the general view of which and of welding wire guiding and rewinding device is shown in Figure 12.

Special brass dies were used for precise basing of wire surface relative to laser beam axis. To prevent oxidation of irradiated surface, shielding gas (argon) was fed into the laser beam impact zone. Special microscope with WEB-camera con-

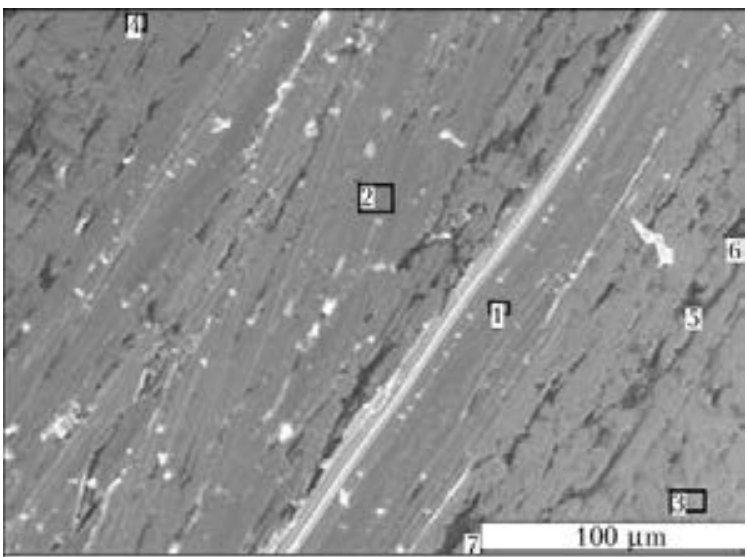

Element content in polished wire spectra, wt.\%

\begin{tabular}{l|c|c|c|c|c|c|c}
\hline Spectrum & $\mathrm{C}$ & $\mathrm{O}$ & $\mathrm{Na}$ & $\mathrm{Si}$ & $\mathrm{Ca}$ & $\mathrm{Mn}$ & $\mathrm{Fe}$ \\
\hline 1 & 1.40 & & & 0.80 & & 2.29 & 95.52 \\
2 & & & & 1.15 & & 1.99 & 96.86 \\
3 & 4.93 & & & 1.19 & & 1.80 & 92.08 \\
4 & 1.66 & & & 0.76 & & 1.85 & 95.73 \\
5 & 51.89 & 9.75 & 0.51 & 0.47 & 1.86 & 0.75 & 34.77 \\
6 & 48.07 & 8.43 & 0.36 & 0.47 & 1.33 & 0.72 & 40.62 \\
7 & 37.59 & 5.41 & 0.43 & 0.27 & 0.78 & 0.99 & 34.32 \\
Max & 51.89 & 9.75 & 0.51 & 1.19 & 1.86 & 2.29 & 96.86 \\
Min & 1.40 & 5.41 & 0.36 & 0.27 & 0.78 & 0.72 & 34.77
\end{tabular}

Figure 10. RSPMA results for $1 \mathrm{~mm}$ wire after polishing

nected to a computer, providing from 25- to 100fold magnification, was used for observation of laser treatment process. Laser radiation power was adjusted within 700 to $1200 \mathrm{~W}$. During laser treatment, the wire was rewound from passive spool onto drive spool. Speed of wire displacement relative to laser beam was varied in the range of 1.5 to $3.5 \mathrm{~m} / \mathrm{min}$.

Two samples of $1.2 \mathrm{~mm}$ welding wire each $10 \mathrm{~m}$ long were subjected to laser treatment. One sample was subjected to laser treatment from one side only, and the other was treated from two opposite sides. First one side was treated, then the wire was turned through $180^{\circ}$, and the other side was irradiated.

During laser treatment enhanced brightness flashes were continuously pulsing over the irra-
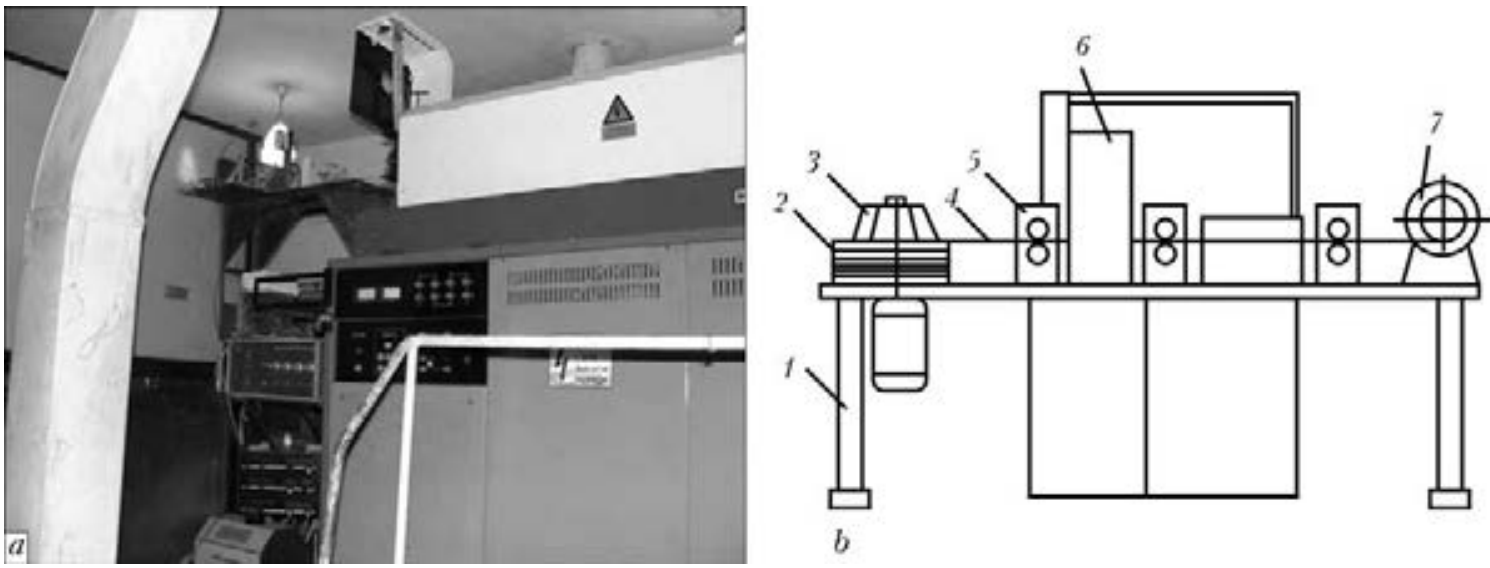

$b$

Figure 11. «Kometa-2» laser system $(a)$, and diagram of the device for welding wire guiding and rewinding relative to the laser beam $(b)$ (for designations see the text) 


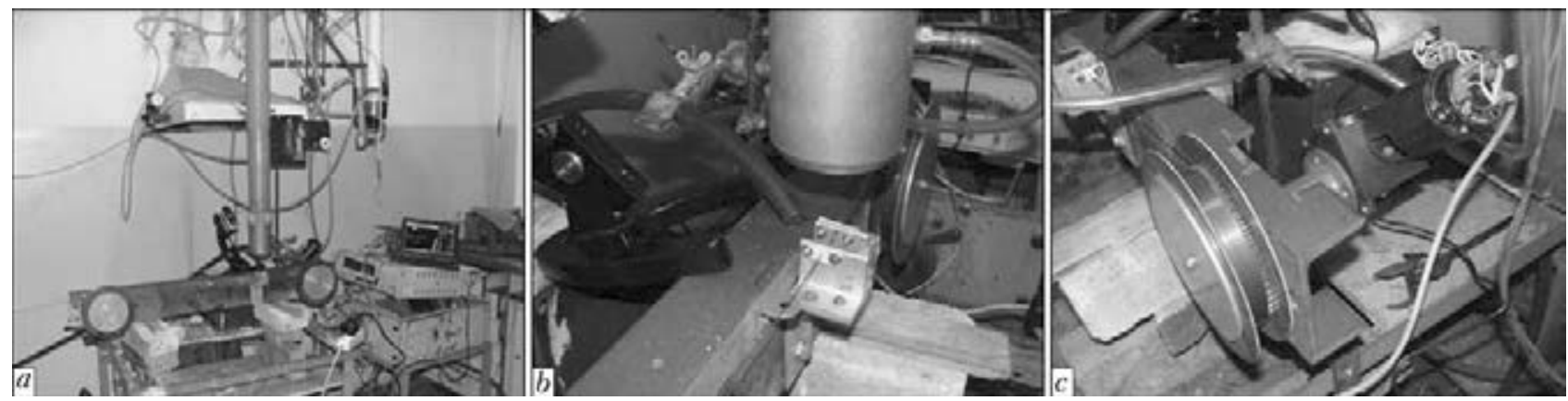

Figure 12. General view of the system $(a)$ and its individual devices designed for guiding $(b)$ and rewinding $(c)$ of welding wire at its surface treatment by $\mathrm{CO}_{2}$-laser radiation

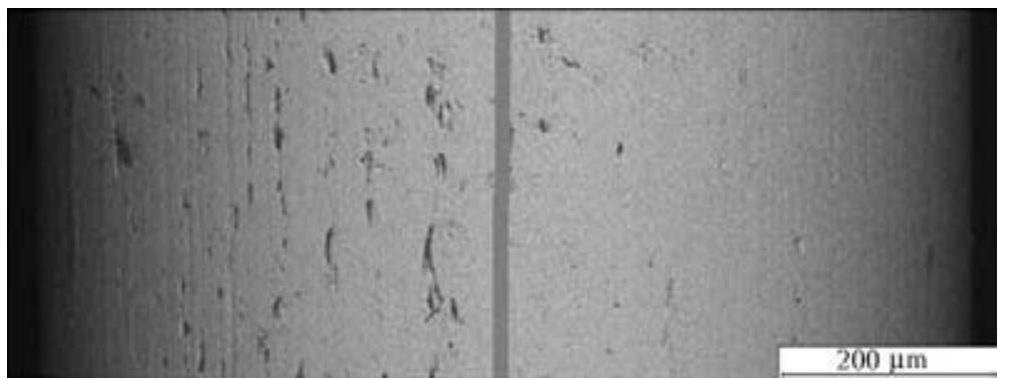

Figure 13. Electron micrograph of copper coating surface on the wire treated (right side) and untreated (left) by laser radiation

diated wire surface that is, probably, due to oxide evaporation.

After laser treatment samples were cut out from two wire types and were studied by the methods of light and scanning electron microscopy. Copper coating was applied onto the main part of two wire samples under production conditions.

Results of examination of the quality of copper coating on welding wire pretreated by laser. Figure 13 gives the electron micrograph of coating surface, including the zone treated by laser radiation, and zone not subjected to laser treatment. It is seen that laser pre-treatment of wire surface leads to formation of coating with much

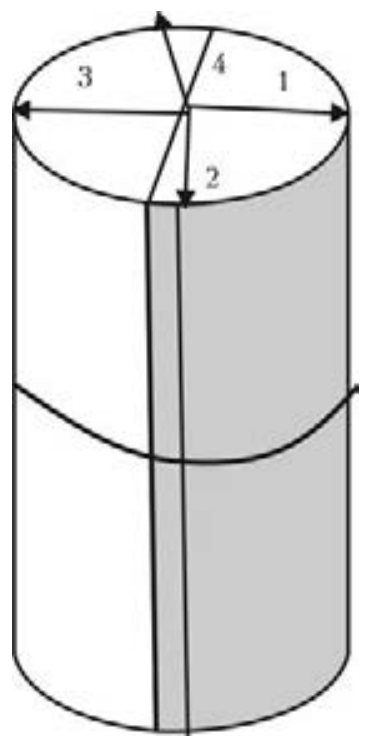

Figure 14. Schematic of defect location relative to the center of treated $(1$, gray $)$ and untreated $(3$, white) surface (for designations see the text) smaller number of defects. Their presence near the boundary line (see gray band in Figure 13, and zone 2 in Figure 14) on the treated side is attributable to non-uniform distribution of radiation power density over the wire cylindrical surface. The central part of its irradiated zone 1 (Figure 14) has practically no such inclusions. Such non-uniformity of inclusion distribution is readily removed by application of a laser beam with torroidal distribution of intensity.

Analyzing these results, it is rational to clarify the nature of defects in the treated zone, whether they contain oxide remains and whether there is coating on defects in both zones.

RSPMA of defects was performed to provide replies to the above questions. The object was revolving about the wire axis and after rotation through an angle of $\sim 90^{\circ}$, defect micrograph was taken and its composition was determined. Schematic of defect location on the wire is given in Figure 14, and their electron micrographs and element content are given in Figure 15. Results obtained in zone 4 are equivalent to zone 3 .

Examination of defects seldom found in the center of treated wire surface (Figure 15, $a$ ) showed that they contain a small amount of iron oxides, on the surface of which copper layer was deposited. Laser treatment of the wire peripheral surface by lower-intensity radiation leads to a certain increase of defect concentration and of oxide content level (Figure 15, b). In wire sections, not subjected to laser treatment, defect concentration was by an order of magnitude higher than in the center of irradiated surface. Oxide quantity in it changes in a very broad 

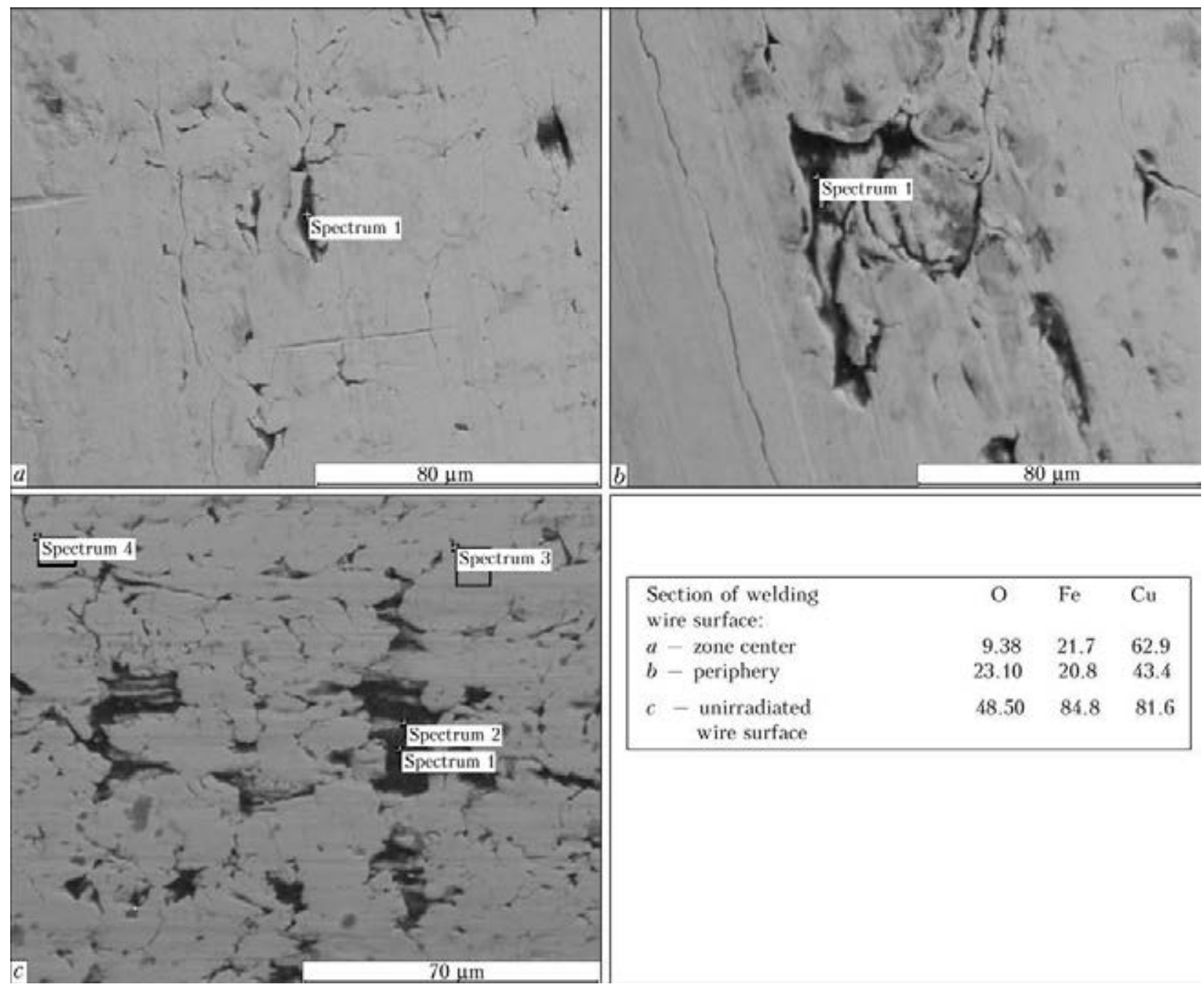

Figure 15. Electron micrographs of defects in zone 1 (center of wire irradiated surface) (a), in zone 2 (peripheral part of the zone) $(b)$ and in zone 3 (unirradiated surface) $(c)$

range (from 2 up to $48.55 \%$ ). Here, copper coating is practically absent in the majority of wire sections containing oxides. At two-sided laser treatment the number of wire sections with oxides, and, hence, without the copper coating, is essentially smaller. They, however, are present on the side surfaces.

\section{Conclusions}

1. Laser treatment of welding wire by continuous radiation with $10.6 \mu \mathrm{m}$ wave length significantly reduces the quantity of oxides in surface defects.

2. Volumes freed from oxides on welding wire surface are filled with copper at subsequent coating deposition.

3. Mechanism of oxide removal consists in a marked increase of their volume as a result of high-rate laser heating.

4. For uniform removal of oxides from the entire cylindrical surface of wire, it is rational to focus the laser radiation using a torroidal mirror.

1. Sychkov, A.B., Zhigarev, M.A., Zhukova, S.Yu. et al. (2008) Formation of optimal properties of scale on rolled wire surface. Bendery: Poligrafist.
2. Parusov, V.V., Sanyuk, A.N., Syckhov, A.B. (2004) Study of possibility of more complete removal of scale from rolled wire surface before drawing. Metallurg, 6, 6-28.

3. Parusov, V.V., Sychkov, A.B., Zhigarev, M.A. (2006) Study of possibility to remove the scale from the surface of rolled wire from Sv-08G2S steel. $M e^{-}$ tallurgich. $i$ Gornorudn. Promyshlennost, 5, 23-29.

4. Kozlov, E.I., Dekhtyaryov, V.G., Novikov, M.P. (1981) Electrochemical cleaning of Sv-08G2S wire surface. Avtomatich. Svarka, 9, 46-48.

5. Dalsky, A.M., Barsukova, T.M., Bukharkin, L.N. et al. (2004) Technology of structural materials: Manual for higher educational institution students of machine-building specialities. 5th ed. Moscow: Mashinostroenie.

6. (2002) Methods of manufacturing copper-coated welding wire. Svarochn. Proizvodstvo, 3, 41-43.

7. Medyushko, V.A., Razorenov, O.N. (2007) Some peculiarities of metallurgical processing and application of Sv-08G2S type wire in mechanized welding processes. Industriya, 32(5), 21-23.

8. www.spetechsoyuz.com. Technological properties of welding wire

9. Brandon, D., Kaplan, W. (2004) Microstructure of materials. Methods of examination and control. Moscow: Tekhnosfera.

10. Sychkov, A.B., Zhigarev, M.A., Zhukova, S.Yu. (2007) Ensuring scale removal from rolled wire surface before drawing. Metizy, 15(2), 48-54. 